\title{
A safer, effective treatment for autoimmune glomerulonephritis
}

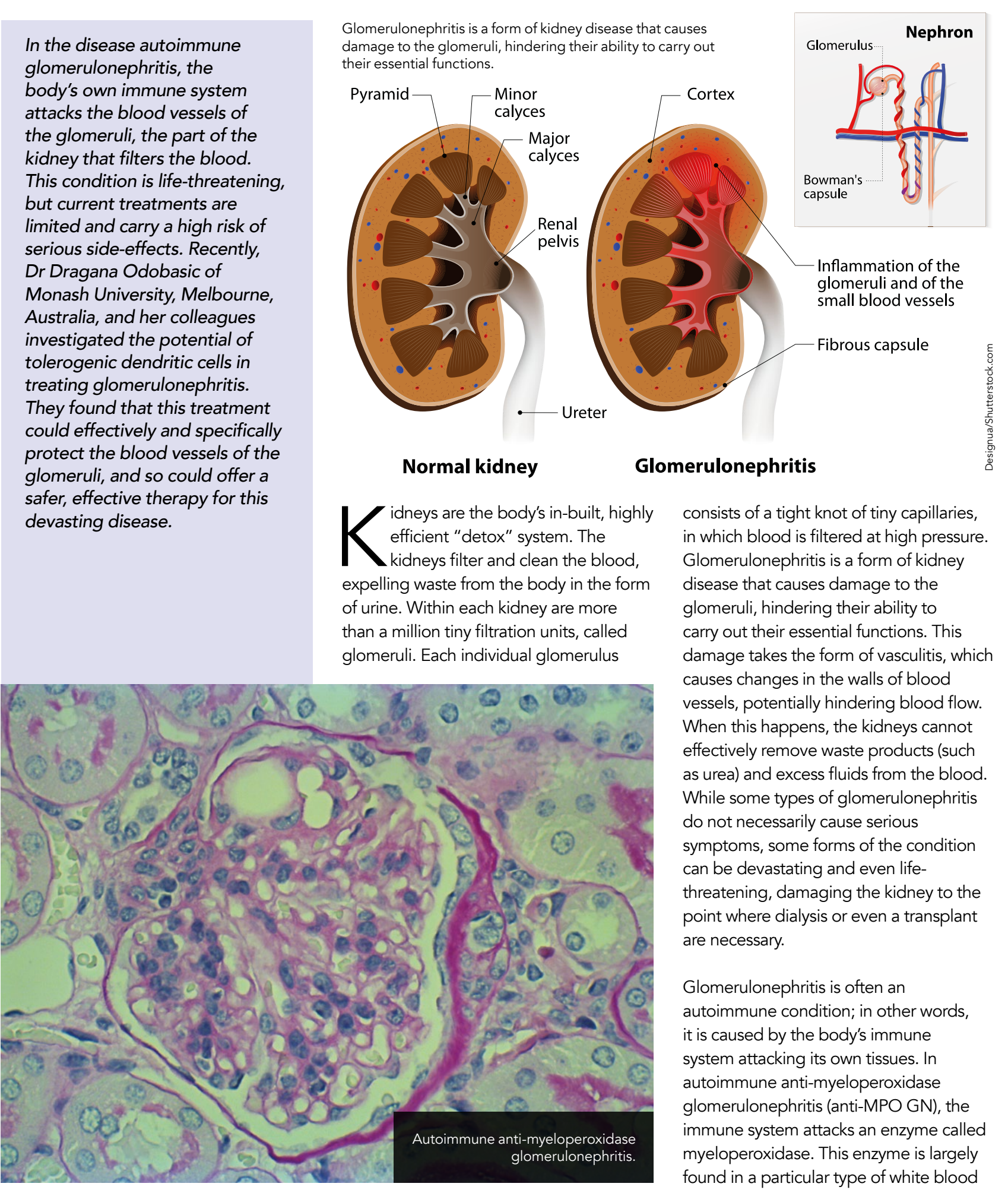

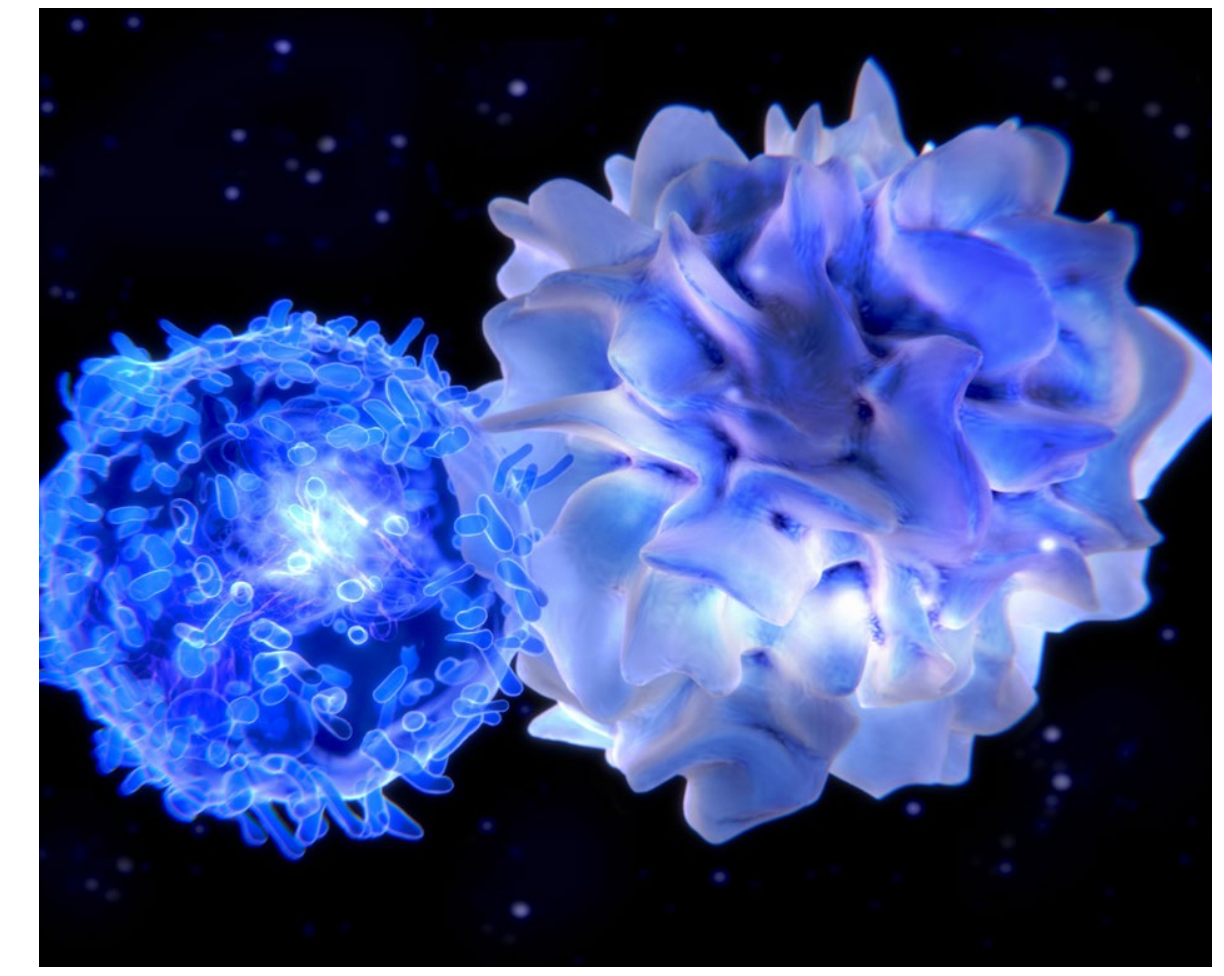

In anti-MPO GN the white blood cells appear to target the glomeruli.

cells, which are an important part of the body's immune defences. Normally, these white blood cells destroy invasive pathogens such as bacteria. In anti-MPO ap, however, the white blood cells Anti-MPO GN is a life-threatening condition thas ilfe-threatening of the small blood vessels in the kidneys. Current treatment options for anti-MPO GN are limited. The medications that are available are only partially effective, and are associated wh many adverse effects; broad suppression of the immune system, the patient has a high risk of contracting a serious infection. Safer, more specific treatments for anti-MPO GN are needed. Ideally, these treatments should supress only the anti-MPO immune response, an thus protect the kidneys from damage.

\section{EXPLORING TOLEROGENIC} DENDRITIC CELLS

Dr Dragana Odobasic of Monash University, Australia, leads research into safer treatments for autoimmune kidney disease. In a recent study, Dr Odobasic and her colleagues investigated the potential of a particular group of cells, called tolerogenic dendritic cells, in developing
MPO GN.
Dendritic cells play an important role in adaptive immunity - immunity that arises after exposure to a pathogen (or a vaccination). Activated, or mature, factor in some types of autoimmun disease. However, immature dendritic

Tolerogenic dendritic cells promote immunosuppression, and could therefore fulfil the need for a specific, targeted treatment for anti-MPO GN. $\begin{array}{ll}\text { cells can help to prevent over-activity of } & \text { with MPO so they can present it and } \\ \text { the immune system, through inhibiting a } & \text { therefore turn off MPO-specific T cells }\end{array}$ type of immune cell called T-cells. These immature cells are termed tolerogenic dendritic cells, because they promote "tolerance" (unresponsiveness) in the immune system.

Tolerogenic dendritic cells promote immunosuppression in a specific manner and could therefore fulfil the need for a more targeted treatment for anti-MPO GN. These cells have already been used in phase 1 trials (which test the safety and toxicity of a drug) in patients with other autoimmune diseases. The results have been promising. Dr Odobasic
and her colleagues suspected that the which cause anti-MPO GN. Through this treatment could be particularly successful response targets a specific, known many patients with acute anti-MPO GN damage to the kidneys can be at least partially reversed with effective treatment reducing the need for a kidney transplant or dialysis. team investigated whether tolerogenic MPO-specific autoimmunity and thereby . MOUSE MODEL SHEDS LIGHT ON AUTOIMMUNITY

To understand more about the disease pathway of anti-MPO GN, Dr Odobasic mouse model that closely resembles the team first created suitable tolerogenic dendritic cells by culturing mouse bone marrow cells with a range of carefullyselected substances. These included an inhibitor of the protein complex $\mathrm{NFkB}$, which plays a major role in the pathogen-fighting and proinflammatory abilities of dendritic cells. Importantly,

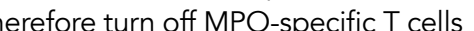
process, the team successfully created tolerogenic dendritic cells that are able to specifically turn off only autoimmunity against myeloperoxidase.

Next, the team induced anti-MPO GN disease in a number of mice. These mice were then treated with the tolerogenic dendritic cells. As the team had hoped, the results showed that injecting tolerogenic dendritic cells can successfully, and precisely, "switch off" anti-MPO autoimmunity, without affecting Specifically, the researchers discovered 


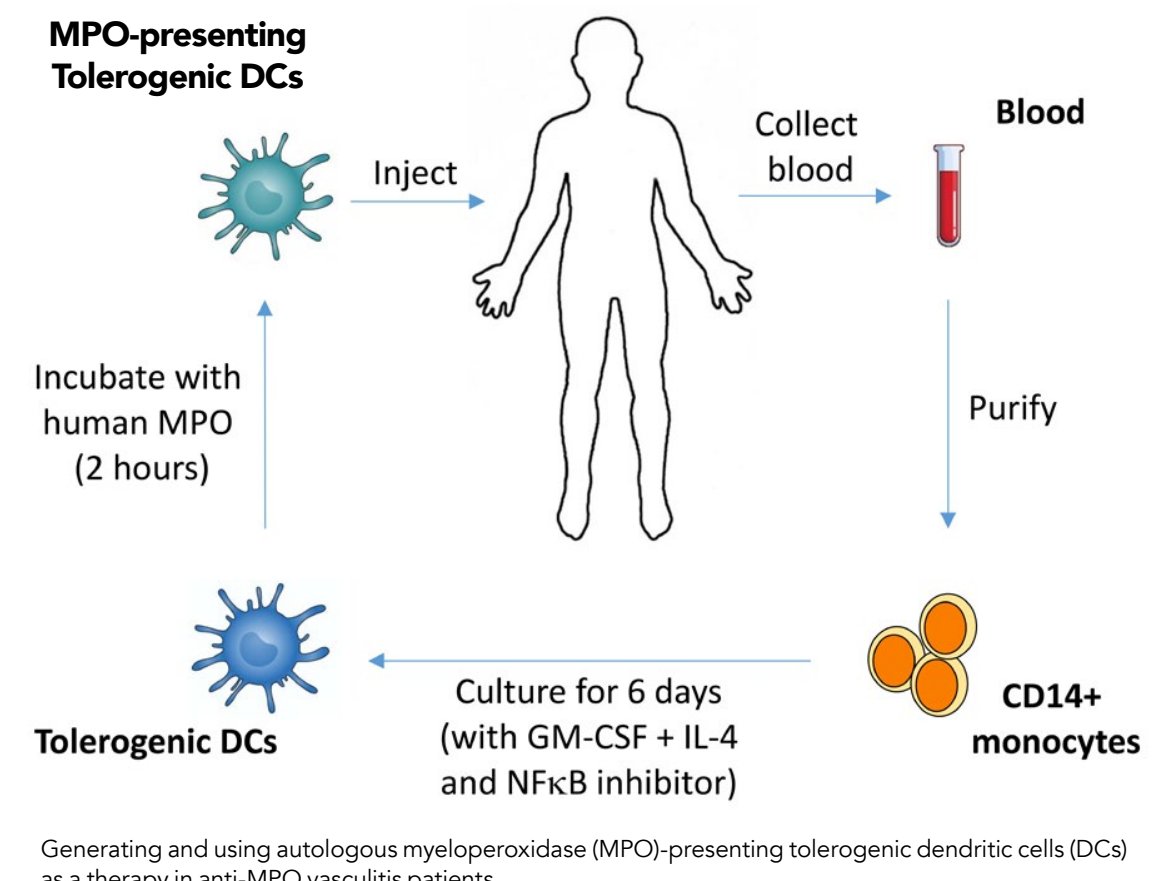

Generating and using autologous myeloperoxid

\section{Injecting MPO-presenting}

tolerogenic dendritic cells can successfully and precisely "switch off" anti-MPO autoimmunity.

that the dendritic cells suppressed the activity of several types of injurious white blood cells, including CD4 T cells, CD8 T cells and B-cells. In this way, the dendritic cells prevented the damage to blood vessels that is characteristic of glomerulonephritis.

The team also discovered that the tolerogenic dendritic cells were able by inducing a type of immune celly called regulatory $\mathrm{T}$-cells. Regulatory $\mathrm{T}$ cells, as the name suggests, regulate the activity of the immune system; crucially, these cells maintain tolerance of self-antigen (proteins expressed by the body's own cells) and help to prevent autoimmune disease.

Dr Odobasic suspects that, although the tolerogenic dendritic cells only survive in the recipient for a few weeks. their effects may last for much longer. In addition, administering multiple doses of tolerogenic dendritic cells
should create stronger, longer-lasting should create stronger, longer-lasting ability to protect the kidneys.
These blood cells would then be purified and treated whth an NFKB inhibitor, and The cells would then be injected back into the same patient, eliminating the risk of rejection. Hopefully, this will allow the researchers to demonstrate that a patient's own tolerogenic dendritic cells have the ability to switch off their autoimmunity to MPO. Dr Odobasic also plans to test other types of tolerogenic dendritic cells in anti-MPO GN because the effectiveness and precise mechanism of immunosuppression varies betwee different types of tolerogenic dendritic cells. This will allow the team to identify

Ultimately, the researchers hope that positive results from this research will allow them to lead a world-first clinical treating anti-MPO GN from their bas at Monash University, Australia.

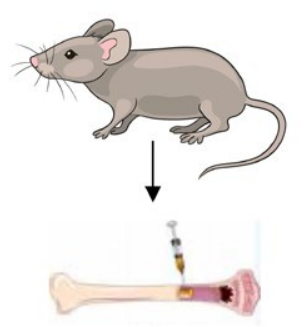

\section{A TARGETED TREATMENT FOR}

AUTOIMMUNE DISEASE

DrOdobasic's work has demonstrated

for the first time, that injecting

tolerogenic dendritic cells can specifically "switch off" anti-MPO autoimmunity an protect the glomerul from vasculitis. In addition, other researchers have used differentatoimmune diseses, with similarly promising results.

Together, these results strongly suggest that tolerogenic dendritic cells cougld be new, effective and safe treatment for antiMPO GN. Such a treatment would be a huge benefit for anti-MPO GN patients, improving their quality of life and allowing them to avoid the dangerous side effects that accompany many of the current, non-specific, treatments. In fact, these cells could potentially offer an effective cure for anti-MPO GN, by preventing damage to the tiny blood vessels of the glomerut.

In future, Dr Odobasic and her colleagues plan to further their research by collecting

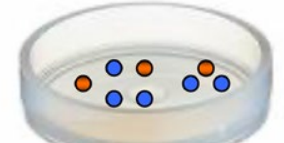

$\downarrow$ Purify DCs<smiles>C1=C[C@@H]2C[C@@H]12</smiles>

$\downarrow+\mathrm{MPO}$

०००० pros use in the thogenic dendritic cells $\left(D C_{5}\right)$ glomerulonephritis (GN): . Isolate bone marrow from mice.

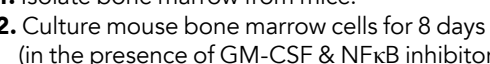
(195\% CD11+c cells). mouse MPO (2 hours).
mouse

\section{Behind the Research}

\section{Dr Dragana Odobasic}

E: dragana.odobasic@monash.edu T: 0412988356

https://research.monash.edu/en/persons/dragana-odobasic

\section{Research Objectives}

The aim of Dr Odobasic's research is to find better targeted treatments for autoimmune kidney disease.

\section{Detail}

Department of Medicine, Centre for Inflammatory Diseases Monash University, Monash Medical Centre Clayton VIC 3168, Australia

Bio

Dr Odobasic is a Research Fellow and an Emerging Leader in the Department of Medicine, Centre for Inflammatory Diseases, Monash University, Melbourne, Australia. Her main research focus is to find safer treatments for cell therapies including tolerogenic $D C s$, regulatory $T$ cells and stem cells.

Funding

$\downarrow+$ GM-CSF, NFKB inhibitor

Generation of myeloperoxidase (MPO)(in the presence of $G M-C S F$ \& NFKB inhibitor)
3. Enrich DCs by anti-CD11c microbeads

Aational Health Medical Research Council of Australia (NHMRC)

\section{References}

Odobasic, D, et al. 2019. Tolerogenic Dendritic Cells Attenuate Experimental Autoimmune Antimyeloperoxidase ASN.2019030236

\section{Personal Response}

Do you plan to explore the use of tolerogenic dendritic forrong basis for testing tolerogenic DCs as a therapy Goodpasture's syndrome and anti-Proteinase 3 vascultitis. For those conditions, the current therapies consist of the same toxic, non-specific immunosuppressants and the target autoantigens are also known. So, we plan to test tolerogenic
dendritic cells in those diseases, too.

MONASH

University

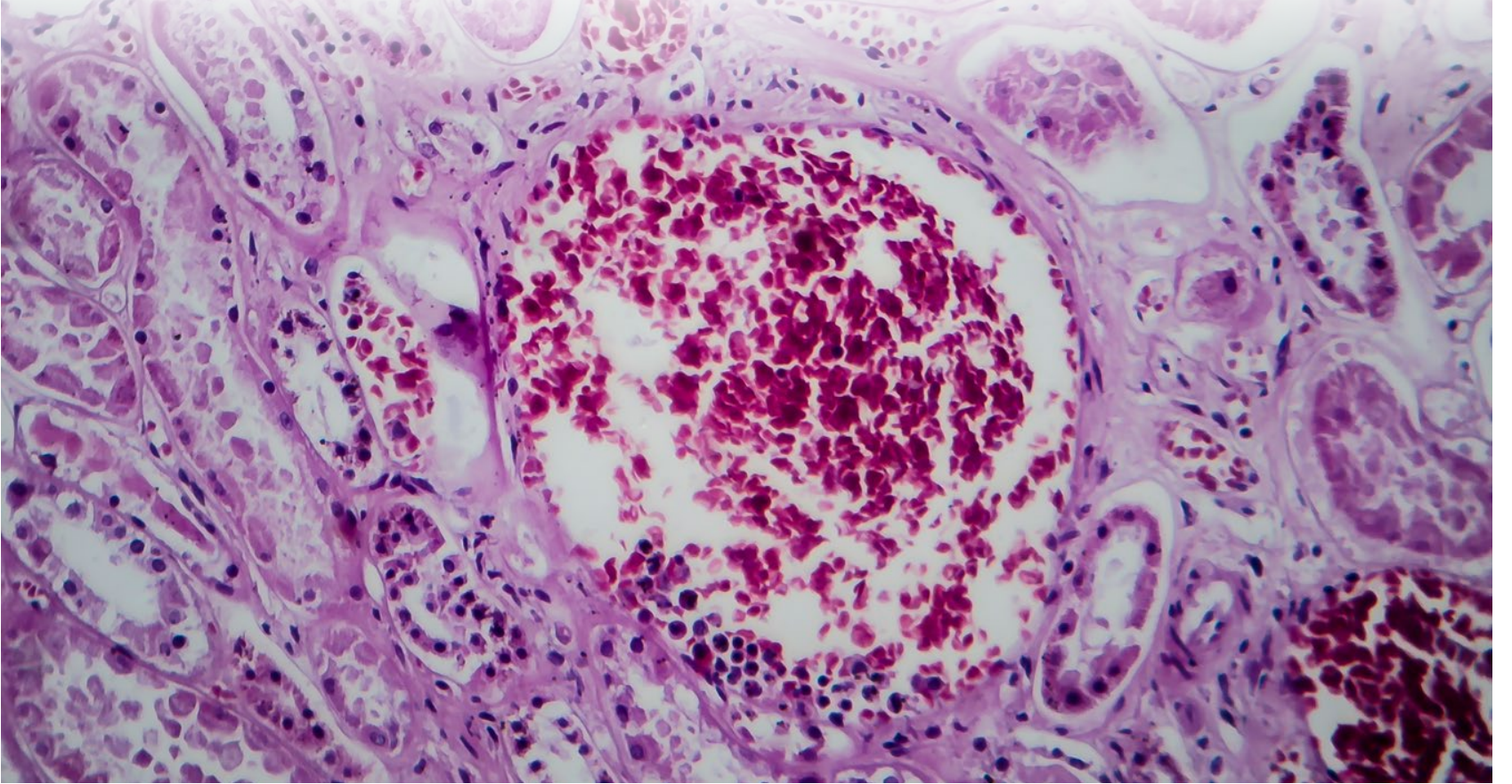

II Our published results in anti-MPO GN have formed 